\title{
THE OXYGEN CONSUMPTION OF THE NORMAL AND THE DISEASED HUMAN KIDNEY ${ }^{1}$
}

\author{
By WALTER H. CARGILL 2 aND JOHN B. HICKAM \\ (From the Department of Medicine, Duke University School of Medicine, Durham, N. C.)
}

(Received for publication October 18, 1948)

The development of a technique of intravenous catheterization and its application to the sampling of renal venous blood (1) have made possible the study of the metabolic activity of the kidney in the unanesthetized human subject. We have used this method of investigation in conjunction with the usual clearance procedures in an attempt to determine the oxygen consumption of the normal kidney and its variation in disease.

\section{METHODS}

All subjects were studied at rest and in the postabsorptive state. Inulin and sodium para-aminohippurate (PAH) clearances were performed as described by Goldring and Chasis (2), urine being collected by bladder catheterization. Following the injection of the priming doses and the starting of the sustaining infusion of inulin and $\mathrm{PAH}$, a modified ureteral catheter was introduced into an antecubital vein of the opposite arm, and passed under fluoroscopic visualization through the right atrium and inferior vena cava and into the right renal vein. The rotation of the curved tip of the catheter posteriorly, and other details of technique have been described by Bradley (3), and by Warren, Brannon, and Merrill (1). Urine was collected at accurately timed intervals of 10-30 minutes, and at approximately the midpoint of each urine collection period blood samples were obtained from a femoral artery and the right renal vein. There was usually an interval of one or two minutes between the withdrawal of these samples. A portion of each sample was collected anaerobically, either under mineral oil, or in an oiled heparinized or citrated syringe, and the oxygen content determined by the method of Van Slyke and Neill (4). The remainder of the samples were oxalated and centrifuged as soon as possible for the determination of the plasma inulin and PAH content by the methods of Corcoran and Page (5) and Smith et al. (6). From two to six urine collection periods and a corresponding number of pairs of arterial and renal venous blood samples were obtained from each subject. In addition, paired samples of heparinized and oxalated whole blood were obtained from each subject for hematocrit and oxygen capacity determinations.

\footnotetext{
1 Aided by a grant from the Life Insurance Medical Research Fund.

2 Present address: Department of Medicine, Emory University School of Medicine, Atlanta, Georgia.
}

Clearances of inulin and PAH were calculated in the usual manner from the rate of urinary excretion and the arterial levels of these substances. The percentage extraction of $\mathrm{PAH}$ was determined by the formula $\frac{A-R}{A}$ $\times 100$, where $A$ and $\mathrm{R}$ represent the PAH concentrations in arterial and renal venous plasma, respectively, and the renal plasma flow obtained by dividing the clearance of $\mathrm{PAH}$ by the extraction: $\mathrm{RPF}=\frac{\mathrm{C}_{\mathrm{PAB}}}{\mathrm{Ext} \text {. PAH }}$. A discussion of the calculation of renal plasma flow in this manner is presented in a separate publication (7). This figure was corrected for the hematocrit reading to obtain the renal blood flow. The difference in oxygen content between arterial and renal venous blood (renal oxygen extraction), expressed as volume of $\mathrm{O}_{2}$ per cc., was multiplied by the renal blood flow to obtain the renal oxygen consumption: Renal oxygen consumption $=\mathrm{RBF} \times \mathrm{A}_{0_{2}}$ $-R_{\mathbf{O}_{2}}$.

Van Slyke et al. (8) have maintained that the arterialrenal venous oxygen difference is not always a true measure of renal oxygen extraction in the dog, since they found definite differences in the hemoglobin content (oxygen capacity) of arterial and renal venous blood in that animal. In 22 comparisons of the oxygen capacities of paired arterial and renal venous samples we have found a mean difference of 0.2 volume per cent, with a standard error of \pm .01 . Seventy-one comparisons of paired arterial and renal venous hematocrit determinations showed a mean difference of 0.1 per cent packed red cell volume, with a standard error of .07 . These differences are well within the limits of technical error.

Since the arterial-renal venous oxygen difference is quite small, and must be multiplied by a large figure for renal blood flow to obtain the oxygen consumption, the measurement of this difference constitutes a potential source of grave error. All oxygen determinations were done in duplicate and discarded if they did not agree within 0.1 volume per cent. Successive samples of arterial and renal venous blood in a given patient over a one or two hour period usually showed minor fluctuations in oxygen content, the mean difference between successive determinations of $\mathrm{A}-\mathrm{V}$ differences in 31 subjects being 0.05 volume per cent. It is felt that these variations are partly real and partly due to technical error; in any case, they are not of sufficient magnitude to compromise the conclusions we have drawn from our observations.

All figures have been corrected to a standard surface area of $1.73 \mathrm{sq} . \mathrm{m}$. 


\section{RESULTS}

Thirty-six subjects have been studied in this manner. (Additional studies on most of these subjects have been presented in a separate publication [7]). For the presentation of the data they have been divided into four groups, according to the clinical classification of their disease. The first group (Table I) consists of ten patients in whom no organic disease could be demonstrated or who were suffering from a chronic illness unrelated to the kidney. The clinical impression of normal renal function in these subjects was confirmed by the demonstration of normal values for glomerular filtration rate and renal blood flow as established by others. The renal oxygen extraction (arterial-renal venous oxygen difference) is extremely small in comparison with arteriovenous differences elsewhere in the body, ranging from 1.09 to 1.87 volumes per cent, with a mean value of 1.42 volumes per cent. Although the amount of oxygen removed from each unit of blood perfusing the kidney is quite small, the renal blood flow is so large that the total renal oxygen consumption is of considerable magnitude, ranging from 12.0 to $20.8 \mathrm{cc}$. $/ \mathrm{min}$., with a mean value of $16.0 \mathrm{cc} . / \mathrm{min}$.

The second group of subjects consists of patients whose predominant complaint was hypertension, and in whom a history of previous renal disease could not be elicited. In some of them renal damage was clinically demonstrable, as evidenced by albuminuria, reduced phenolsulfonthalein excretion, or hyposthenuria. On purely clinical grounds it was presumed that the impaired renal

TABLE I

Normal subjects

\begin{tabular}{l|c|c|c|c|c}
\hline \hline \multicolumn{1}{c|}{ Pt. } & $\mathrm{C}_{\mathrm{IN}}$ & FF & RBF & $\mathrm{O}_{2 \text { Ext. }}$ & $\mathrm{O}_{2 \text { Cons. }}$ \\
\cline { 2 - 5 } & $c c . /$ min. & & $c c . /$ min. & vols. \% & $c c . /$ min. \\
W. F. W. & 120 & .14 & 1456 & 1.10 & 16.0 \\
A. J. & 115 & .17 & 1057 & 1.13 & 12.0 \\
W. W. & 106 & .14 & 1284 & 1.09 & 14.0 \\
E. W. & 107 & .16 & 932 & 1.73 & 16.1 \\
M. C. & 142 & .17 & 1450 & 1.32 & 19.2 \\
R. M. & 133 & .18 & 1155 & 1.44 & 16.6 \\
R. B. & 92 & .15 & 1029 & 1.87 & 18.2 \\
J. H. & 131 & .23 & 948 & 1.53 & 14.8 \\
R. A. & 115 & .18 & 1401 & 1.48 & 20.8 \\
J. R. H. & 118 & .23 & 835 & 1.46 & 12.2 \\
\hline Mean & 117.1 & .18 & 1155 & 1.42 & 16.0 \\
S.D. & \pm 14.7 & \pm .04 & \pm 229 & \pm .25 & \pm 2.9 \\
\hline
\end{tabular}

TABLE II

Essential hypertension and nephrosclerosis

\begin{tabular}{|c|c|c|c|c|c|}
\hline Pt. & $\mathrm{C}_{\text {IN }}$ & FF & RBF & $\mathrm{O}_{2}$ Ext. & $\mathrm{O}_{2}$ Cons. \\
\hline $\begin{array}{l}\text { I. S. } \\
\text { O. W. } \\
\text { C. M. } \\
\text { B. G. } \\
\text { C. E. } \\
\text { E. T. } \\
\text { M. S. } \\
\text { B. H. } \\
\text { G. B. } \\
\text { I. P. } \\
\text { R. L. }\end{array}$ & $\begin{array}{c}c c . / \min . \\
126 \\
140 \\
143 \\
133 \\
70 \\
97 \\
109 \\
36 \\
10 \\
97 \\
109\end{array}$ & $\begin{array}{l}.17 \\
.19 \\
.22 \\
.24 \\
.23 \\
.28 \\
.25 \\
.19 \\
.07 \\
.18 \\
.23\end{array}$ & $\begin{array}{c}c c . / \min . \\
1196 \\
1237 \\
1160 \\
971 \\
535 \\
590 \\
701 \\
247 \\
212 \\
852 \\
784\end{array}$ & $\begin{array}{l}\text { vols. \% } \\
0.82 \\
1.81 \\
1.49 \\
1.18 \\
1.96 \\
1.54 \\
1.51 \\
1.91 \\
2.09 \\
1.37 \\
0.98\end{array}$ & $\begin{array}{r}c c . / \min . \\
9.8 \\
22.4 \\
17.3 \\
11.5 \\
10.5 \\
9.1 \\
10.6 \\
4.7 \\
4.4 \\
11.7 \\
7.7\end{array}$ \\
\hline $\begin{array}{l}\text { Mean } \\
\text { S.D. }\end{array}$ & $\begin{array}{r}97 \\
\pm 32\end{array}$ & $\begin{array}{r}.21 \\
\pm .02\end{array}$ & $\begin{array}{r}771 \\
\pm 357\end{array}$ & $\begin{array}{r}1.51 \\
\pm .41\end{array}$ & $\begin{array}{r}10.9 \\
\pm 4.2\end{array}$ \\
\hline
\end{tabular}

function in these subjects was secondary to the hypertension, and that the diagnosis of nephrosclerosis was applicable. It will be seen from Table II that the renal blood flow varied in this group from normal to extremely low levels. The oxygen extractions did not vary correspondingly, the mean, 1.51 volumes per cent, being not significantly different from the normal mean.

The six subjects listed under Table III as chronic nephritis were patients who gave histories of long-standing kidney disease and who were found to have severe impairment of renal function. Of these, N. W. and L. H. probably represented chronic pyelonephritis, the others chronic glomerulonephritis, although the clinical differentiation of these diseases was open to question. In spite of the marked reduction in renal blood flow in this group, to a mean value of $353 \mathrm{cc} . / \mathrm{min}$., the renal oxygen extractions were within the normal range

TABLE III

Chronic nephriiis

\begin{tabular}{|c|c|c|c|c|c|}
\hline Pt. & $\mathrm{C}_{\text {IN }}$ & FF & RBF & $\mathrm{O}_{2}$ Ext. & $\mathrm{O}_{2}$ Cons. \\
\hline $\begin{array}{l}\text { J. M. } \\
\text { E. M. } \\
\text { B. R. } \\
\text { N. W. } \\
\text { L. H. } \\
\text { M. L. }\end{array}$ & $\begin{array}{r}c c . / m i n . \\
56 \\
19 \\
17 \\
50 \\
20 \\
21\end{array}$ & $\begin{array}{l}.12 \\
.11 \\
.07 \\
.18 \\
.18 \\
.12\end{array}$ & $\begin{array}{r}c c . / \min . \\
636 \\
245 \\
347 \\
482 \\
168 \\
242\end{array}$ & $\begin{array}{r}\text { ools. \% } \\
1.84 \\
1.30 \\
1.74 \\
1.72 \\
1.60 \\
1.90\end{array}$ & $\begin{array}{r}c c . / \min . \\
11.7 \\
3.2 \\
6.0 \\
8.3 \\
2.7 \\
4.6\end{array}$ \\
\hline $\begin{array}{l}\text { Mean } \\
\text { S.D. }\end{array}$ & $\begin{array}{r}30.5 \\
\pm 17.0\end{array}$ & $\begin{array}{r}.13 \\
\pm .04\end{array}$ & $\begin{array}{r}353 \\
\pm 176\end{array}$ & $\begin{array}{r}1.68 \\
\pm 0.20\end{array}$ & $\begin{array}{r}6.1 \\
\pm 3.3\end{array}$ \\
\hline
\end{tabular}


TABLE IV

Clinical data on patients with glomerulonephritis

\begin{tabular}{|c|c|c|c|c|c|c|c|c|c|c|c|c|c|}
\hline \multirow{2}{*}{ Pt. } & \multirow{2}{*}{ Age } & \multirow{2}{*}{$\underset{\text { tion }}{\text { Dura- }}$} & \multirow{2}{*}{ Edema } & \multirow{2}{*}{ B.P. } & \multirow{2}{*}{ Fundi } & \multicolumn{3}{|c|}{ Plasma } & \multirow{2}{*}{ Hgb } & \multicolumn{3}{|c|}{ Urine } & \multirow{2}{*}{ Remarks } \\
\hline & & & & & & Albumen & $\begin{array}{c}\text { Choles- } \\
\text { terol }\end{array}$ & NPN & & $\begin{array}{l}\text { Pro- } \\
\text { tein }\end{array}$ & $\mathbf{R B C}$ & Casts & \\
\hline T. B. & 22 & 6 weeks & $1+$ & $135 / 85$ & Normal & 3.6 & 260 & 31 & 13.4 & $3+$ & $2+$ & $\underset{\text { granular }}{2+}$ & $\begin{array}{l}\text { Weakness; } \\
\text { severe lumbar } \\
\text { pain }\end{array}$ \\
\hline G. W. & 37 & 8 weeks & $4+$ & $116 / 70$ & Normal & 1.5 & 640 & 33 & 15.0 & $4+$ & $0-1+$ & $\begin{array}{c}2+ \\
\text { hyaline } \\
\& \text { waxy }\end{array}$ & $\begin{array}{l}\text { Asymptomatic } \\
\text { except for } \\
\text { massive edema }\end{array}$ \\
\hline D. R. & 49 & 8 weeks & $3+$ & $160 / 100$ & Normal & 1.7 & 300 & 52 & 13.0 & $3+$ & $0-1+$ & $\begin{array}{c}1+ \\
\text { granular } \\
\text { \& hyaline }\end{array}$ & $\begin{array}{l}\text { Nausea and } \\
\text { vomiting. One } \\
\text { convulsion }\end{array}$ \\
\hline A. $\mathrm{H}$. & 38 & 5 weeks & $1+$ & $145 / 85$ & $\begin{array}{l}\text { Arteriolar } \\
\text { narrowing }\end{array}$ & 1.6 & 440 & 30 & 13.0 & $3+$ & $2+$ & $\underset{\substack{2+\\
\text { granular }}}{2+}$ & $\begin{array}{l}\text { Headache, } \\
\text { blurred vision }\end{array}$ \\
\hline B. $\mathrm{B}$. & 39 & $6 \mathrm{mos}$ & $\mathbf{0}$ & $124 / 88$ & Normal & 2.4 & 200 & 35 & 10.0 & $1+$ & $1+$ & $\underset{\text { granular }}{1+}$ & Arthritis \\
\hline L. D. & 31 & 8 weeks & $2+$ & $130 / 95$ & Normal & 3.0 & 220 & 40 & 12.0 & $2+$ & $2+$ & $\underset{\substack{2+\\
\& R B C}}{\stackrel{2 r a n u l a r}{2}}$ & Headache \\
\hline G. I. & 38 & $5 \mathrm{mos}$ & $3+$ & $145 / 95$ & Normal & 1.7 & 720 & 36 & 15.0 & $2+$ & $0-1+$ & $\underset{\text { granular }}{1+}$ & $\begin{array}{l}\text { Weakness, } \\
\text { headache }\end{array}$ \\
\hline R. E. & 42 & $6 \mathrm{mos}$ & 0 & $200 / 140$ & $\begin{array}{l}\text { Arteriolar } \\
\text { narrowing }\end{array}$ & 2.9 & 250 & 38 & 18.0 & $1+$ & $1+$ & $\underset{\substack{1+\\
\text { granular }}}{\mathrm{RBC}}$ & $\begin{array}{l}\text { Headache, occ. } \\
\text { blurred vision }\end{array}$ \\
\hline W. A. & 21 & 2 years & $1+$ & $150 / 70$ & Normal & 3.8 & 180 & 49 & 16.0 & $1+$ & $1+$ & $\underset{\text { granular }}{1+}$ & $\begin{array}{l}\text { Rheumatic } \\
\text { heart disease }\end{array}$ \\
\hline
\end{tabular}

Significant clinical data on ten patients who were diagnosed as acute or subacute glomerulonephritis are summarized in Table IV. Two of these patients (G. W. and G. I.) were obviously in the nephrotic or "degenerative" stage of the disease, as demonstrated by massive edema, proteinuria and extreme hypoalbuminemia and hypercholesterolemia. In the others, hypertension, hematuria, or a combination of all elements of the disease predominated. W. A. had an attack of hemorrhagic nephritis of several weeks' duration two years preceding the time of study. He had been asymptomatic until one week before admission when he suffered a mild upper respiratory infection, and puffiness of the eyelids and microscopic hematuria were noted. It is felt that he represents an acute exacerbation of a latent glomerulonephritis. The clinical course of patient R. E. was more suggestive of essential hypertension than glomerulonephritis; he was placed in this group because of albuminuria, hematuria, and the discovery of red blood cell casts in his urinary sediment. It is our impression that these findings do not accompany primary hypertension except in the malignant phase.

A consistent finding in all of these patients was a greater reduction in glomerular filtration rate than in renal blood flow, so that the filtration fraction was uniformly low. This is suggestive of primary glomerular disease, and is in keeping with the findings of Earle, Taggert, and Shannon (8). Likewise, the normal values for renal blood flow indicate that the disease process was not of long standing.

It may be seen from Table $V$ that the renal oxygen consumption of these patients varied between extreme limits, from $0.9 \mathrm{cc} . / \mathrm{min}$. to $13.8 \mathrm{cc} . / \mathrm{min}$. Since the blood flows were normal or only slightly reduced, this variation was due almost entirely to changes in oxygen extraction. This is in con- 
trast to the preceding groups, in which variations in blood flow and normal oxygen extractions were found. No correlation existed between the predominant symptomatology in any patient and the oxygen consumption of his kidneys. It is true that patient D. R., whose renal oxygen consumption was extremely low, was also the most severely ill; patient B. B., however, whose kidneys were also consuming comparatively little oxygen, was ambulatory at the time of study. Although the

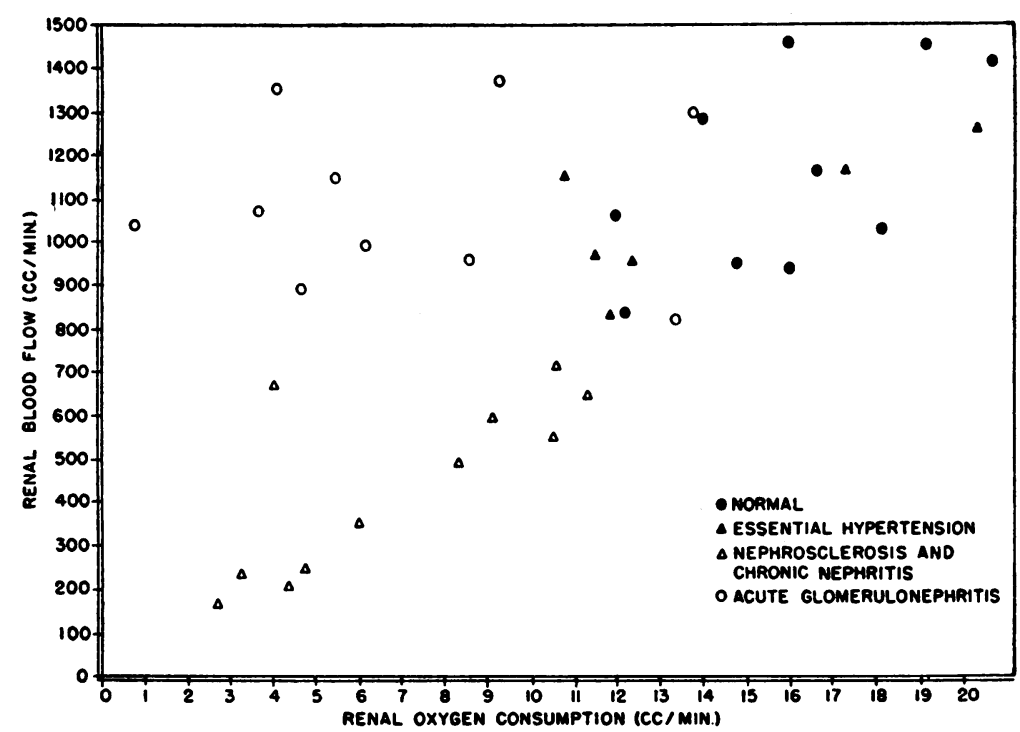

Fig. 1. Renal Blood Flow and Renal Oxygen Consumption in Normal Subjects and in Patients with Hypertension, Nephrosclerosis AND ACUTE Glomerulonephritis

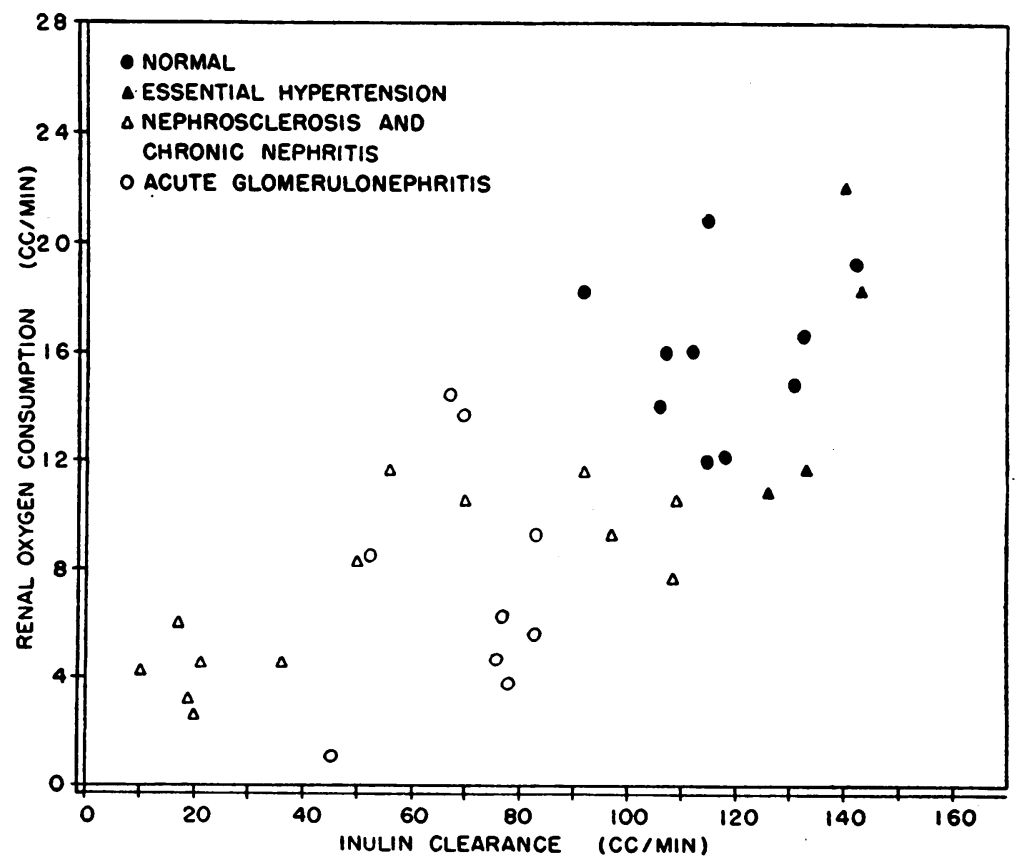

Fig. 2. Renal Oxygen Consumption and Glomerular Filtration Rate in Normal Subjects and in Patients with Hypertension, NephROSCLEROSIS AND ACUTE GLOMERULONEPHRITIS 
TABLE $\mathbf{v}$

Acute and subacute glomerulonephritis

\begin{tabular}{c|r|r|r|r|r}
\hline \hline Pt. & \multicolumn{1}{|c|}{$\mathrm{C}_{\mathrm{IN}}$} & $\mathrm{FF}$ & \multicolumn{1}{|c|}{$\mathrm{RBF}$} & $\mathrm{O}_{2 \text { Ext. }}$ & $\mathrm{O}_{2 \text { Cons. }}$ \\
\hline & $c c . /$ min. & & $c c . /$ min. & vols. \% & cc./min. \\
T. B. & 83 & .12 & 1141 & 0.48 & 5.5 \\
G. W. & 67 & .13 & 816 & 1.64 & 13.4 \\
D. R. & 45 & .08 & 1041 & 0.09 & 0.9 \\
A. H. & 77 & .12 & 994 & 0.62 & 6.2 \\
B. B. & 78 & .10 & 1065 & 0.35 & 3.7 \\
L. D. & 71 & .11 & 1293 & 1.07 & 13.8 \\
G. I. & 83 & .10 & 1362 & 0.68 & 9.3 \\
W. A. & 51 & .09 & 959 & 0.90 & 8.6 \\
R.E. & 76 & .16 & 887 & 0.53 & 4.7 \\
\hline Mean & 70 & .11 & 1062 & 0.71 & 7.3 \\
S.D. & \pm 14 & \pm .03 & \pm 179 & \pm 0.45 & \pm 2.5 \\
& & & &
\end{tabular}

oxygen data in two of these subjects were normal, we consider it noteworthy that the mean values for both oxygen extraction and renal oxygen consumption for the entire group are distinctly below the normal range.

The data may be represented graphically as in Figure 1, where renal blood flow is plotted against oxygen consumption. The scatter in the normal range is large, but it is clearly evident that as the renal blood flow falls in chronic renal disease there is a corresponding fall in renal oxygen consumption. In contrast, the majority of the patients with acute and subacute glomerulonephritis are distinguished by a low oxygen consumption with a normal renal blood flow. This difference disappears when oxygen consumption is plotted against glomerular filtration rate, as in Figure 2. Although there is no apparent relation between these factors in any one group, a definite correlation $(r=.76)$ exists when all 36 subjects are considered.

\section{DISCUSSION}

The rate of oxygen utilization by an organ is generally considered to be an expression of its metabolic activity. The metabolism of the normal mammalian kidney has been the subject of numerous investigations (9-12), all of which have demonstrated that renal oxygen consumption is quite high in relation to the weight of the organ, and that this high oxygen consumption is the result of a small arterio-venous oxygen difference (oxygen extraction), and a large renal blood flow.

Van Slyke et al. (9) and others $(11,12)$ have observed in the dog that renal oxygen extraction remains constant when renal blood flow is varied, so that the rate of oxygen consumption is a function of blood flow. Similar results have been obtained in man by Bradley and Halperin (13), who used the technique of intravenous catheterization to determine renal oxygen consumption before and during reduction of renal blood flow by abdominal compression. These authors also observed that the reduced oxygen consumption found during the period of decreased blood flow was associated with apparent cessation of urine formation in a certain proportion of nephrons, and suggested the possibility that "renal oxygen consumption depends upon the relative proportion of tubular tissue actively functioning in the formation of urine from glomerular filtrate."

In this view, it seems logical to expect that renal oxygen consumption would vary with filtration rate if the amount of functioning tubular tissue remained unchanged. Our data show that the kidneys of patients with acute and subacute glomerulonephritis, which had low rates of glomerular filtration, also had low rates of oxygen utilization, in spite of normal or increased blood flow. Earle, Taggert, and Shannon (8) have shown that although the total amount of functioning tubular tissue (as estimated from diodrast $\mathrm{Tm}$ ) tends to fall with the filtration rate, the ratio of filtration rate to $\mathrm{Tm}$ is lower than normal in the early stages of glomerulonephritis, so that there is a greater depression of filtration than of tubular function. It is conceivable that the observed reduction in renal oxygen consumption in our patients was due to decreased formation of glomerular filtrate. An alternative explanation is that in acute and subacute glomerulonephritis there is a fundamental alteration in the metabolic activities of renal cells which results in a diminished utilization of oxygen.

It is of interest in this connection that we have found a definite correlation between filtration rate and oxygen consumption in all our subjects (Figure 2).

The progressive vascular occlusion and destruction of renal parenchyma which result in the granular, contracted kidneys of nephrosclerosis and chronic nephritis are accompanied by decreases in both blood flow and oxygen consumption (Figure 1). It is probable that the diminished oxygen consumption found in these patients is simply a reflection of the lowered metabolic demands of the 
functionally smaller kidneys, the volume of blood flow being an expression of the amount of surviving tissue.

Merrill (14) has found that the decreased renal blood flow accompanying congestive heart failure is compensated for by an increased oxygen extraction, so that oxygen consumption remains normal. (We have found extractions of 3.6 and 4.2 volumes per cent, values significantly greater than our normal mean, in two subjects with congestive failure who are not included in the present series.) Glomerular filtration rate was also reduced in these patients. If filtration rate determines tubular work, and therefore renal oxygen consumption, it is necessary to suppose that independent tubular activity is increased in congestive heart failure.

Although the kidneys of the patients with acute and subacute glomerulonephritis were consuming comparatively little oxygen, they were carrying on all of the functions which are generally considered to constitute renal work, including the reabsorption of water and electrolytes against osmotic gradients, the excretion of urea, and the tubular secretion of PAH. The disproportion between the oxygen consumption of the kidney and the theoretical thermodynamic requirements of known renal work has been pointed out by Barcroft and Brodie (10), Glaser et al. (11), and Van Slyke et al. (9). These last investigators concluded that "the overwhelmingly greater part of the energy produced must be utilized by the kidney for its own internal cellular processes not related to the external work which the organ is performing." Since the nature of these internal cellular processes is completely obscure, it is not inconceivable that their activity, and consequently the demand of the kidney for oxygen, may vary within wide limits without being detectable by known methods of measurement.

In view of the extensive speculation concerning the relation of renal ischemia to essential hypertension our observations in patients with this disease are of interest. Pathologists agree that longstanding hypertensive disease is usually associated with progressive narrowing and even occlusion of small renal blood vessels, particularly the preglomerular arterioles. The functional counterpart of this constriction of the renal vascular bed is evident in some of our patients, in whom definite reductions of renal blood flow were found.
Since the decreased blood flow was not accompanied by an increased oxygen extraction, the oxygen consumption of these kidneys was also low.

The question of whether these vascular changes precede or follow the hypertension has been the subject of much debate. In four patients with sustained hypertension of at least six months' duration we have found normal values for renal blood flow and oxygen consumption, which demonstrates that in at least some cases of essential hypertension the metabolic activities of the kidney are carried on at the normal level.

\section{SUMMARY AND CONCLUSIONS}

1. Renal oxygen consumption in unanesthetized human subjects has been estimated by combining the techniques of intravenous catheterization and sodium para-aminohippurate clearance.

2. The mean normal renal oxygen extraction was found to be 1.42 volumes per cent, and the mean normal renal oxygen consumption $16.0 \mathrm{cc}$./ $\min$.

3. Decreased levels of oxygen consumption were found in patients with nephrosclerosis, chronic glomerulonephritis, and chronic pyelonephritis, who also had diminished renal blood flow. Oxygen extraction was normal in these patients.

4. In patients with acute and subacute glomerulonephritis the extraction of oxygen was decreased in spite of a normal or increased renal blood flow.

The authors wish to thank Dr. E. A. Stead, Jr., for advice and encouragement, and the following for technical assistance: Miss Regina Frayser, Mrs. Juanita M. Clontz, Miss Eloise Covington, and Mrs. Louise Allen.

\section{BIBLIOGRAPHY}

1. Warren, J. V., Brannon, E. S., and Merrill, A. J., Method of obtaining renal venous blood in unanesthetized persons with observations on extraction of oxygen and sodium para-amino hippurate. Science, 1944, 100, 108.

2. Goldring, W., and Chasis, H., Hypertension and Hypertensive Disease. The Commonwealth Fund, New York, 1944.

3. Bradley, S. E., and Bradley, G. P., The effect of increased intra-abdominal pressure on renal function in man. J. Clin. Invest., 1947, 26, 1010. 
4. Van Slyke, D. D., and Neill, J. M., The determination of gases in blood and other solutions by vacuum extraction and manometric measurement. J. Biol. Chem., 1924, 61, 523.

5. Corcoran, A. C., and Page, I. H., Applications of diphenylamine in determination of levulose in biological media; determination of inulin, determination of levulose in small amounts of blood. J. Biol. Chem., 1939, 127, 601.

6. Smith, H. W., Finkelstein, N., Aliminosa, L., Crawford, B., and Graber, M., The renal clearances of substituted hippuric acid derivatives and other aromatic acids in dog and man. J. Clin. Invest., 1945, 24, 388.

7. Cargill, W. H., The measurement of glomerular and tubular plasma flow in the normal and diseased human kidney. J. Clin. Invest., 1949, 28, 533.

8. Earle, D. P., Jr., Taggert, J. V., and Shannon, J. A., Glomerulonephritis; a survey of the functional organization of the kidney in various stages of diffuse glomerulonephritis. J. Clin. Invest., 1944, 23, 119.
9. Van Slyke, D. D., Rhoads, C. P., Hiller, A., and Alving, A. S., Relationships between urea excretion, renal blood flow, renal oxygen consumption, and diuresis; the mechanism of urea excretion. Am. J. Physiol., 1934, 109, 336.

10. Barcroft, J., and Brodie, T. G., The gaseous metabolism of the kidney. J. Physiol., Lond., 1905, 32, 18.

11. Glaser, H., Laszlo, D., and Schürmeyer, A., Utber den Energieumsatz der Niere. Arch. f. exper. Path. u. Pharmakol., 1932, 168, 139.

12. Levy, S. E., Light, R. A., and Blalock, A., The blood flow and oxygen consumption of the kidney in experimental renal hypertension. Am. J. Physiol., 1938, 122, 38.

13. Bradley, S. E., and Halperin, M. H., Renal oxygen consumption in man during abdominal compression. J. Clin. Invest., 1948, 27, 635.

14. Merrill, A. J., Edema and decreased renal blood flow in patients with chronic congestive heart failure; evidence of "forward failure" as the primary cause of edema. J. Clin. Invest., 1946, 25, 389. 